bazole chemistry. We are also grateful to the Deutsche Forschungsgemeinschaft (Bonn, Bundesrepublik Deutschland), the Fonds der Chemischen Industrie, and Boehringer Ingelheim $K G$ for generous financial support of our synthetic work in this area.

Reccived: February 20, 1990 Revised form: July 7, 1990

[1] J.A. Joule, Adv. Heterocycl. Chem. 1984, 35, 83.

[2] D. P. Chakraborty, Planta Med. 1980, 39, 97

[3] K.S. J. Stapleford, in 'Rodd's Chemistry of Carbon Compounds', Ed. M. F. Ansell, Elsevier, New York, 1985, Vol.IV, Part B, p. 71.

[4] H.P. Husson, in 'The Alkaloids', Ed. A. Brossi, Academic Press, New York, 1985, Vol. 26, p. 1 .

[5] D.P. Chakraborty, in 'Prog. Chem. Org. Nat. Products', Eds. W. Herz, H. Grisebach, and G.W Kirby, Springer Verlag, Vienna, 1977, Vol.34, p. 299

[6] P. Bhattacharyya, D.P. Chakraborty, in 'Prog. Chem. Org. Nat. Products', Eds. W. Herz, H. Grisebach, G.W. Kirby, and Ch. Tamm, Springer Verlag, Vienna, 1987, Vol. 52, p. 159

[7] W. L. Albrecht, R.W. Fleming, W.S. Horgan, G. D. Mayer, J. Med. Chem. 1974, $20,364$.

[8] A. Mooradien, A. G. Havac, P.E. Dupon, M. R Bell, A. D. Abousi, J. Med. Chem. 1975, 18, 640.

[9] N. I. Andreeva, Farmak. Toks. 1967, 36, 713 (CA. $1968,68,57793 \mathrm{r}$ ).

[10] D. P. Chakraborty, K.C. Das, B. K. Chowdhury, Trans. Bose Res. Inst. 1975, 38, I; ibid. 1975, 38, 3

[11] G. D. Shah, B. P. J. Patel, Ind. J. Chem. 1979, 188 451 .

[12] K. Sakano, K. Ishimaru, S. Nakamura, J. Antibiot. 1980, 33, 683; S. Nakamura, Trans. Bose Res. Inst. 1984, 47, 69
[13] T. Tabka, J.-F. Heron, P. Gauduchon, J.-Y. Le Talaer, J.-C. Lancelot, S. Rault, M. Robba, Eur. J. Med. Chem. 1988, 23, 119

[14] U. Pindur, Pharmaz. Uns. Zeit 1987, 16, 47.

[15] M.J.E. Hewlins, A.-M. Oliveira-Campos, P. V. R. Shannon, Synthesis 1985, 289.

[16] P. Potier, Pure Appl. Chem. 1986, 58, 737.

[17] A. Ahond, H. Fernandez, M.-J. Moore, C. Poupat, V. Sanchez, P. Potier, S. K. Kan, T. Sevenet, J. Nat. Prod. 1981, 44, 193.

[18] G.W. Gribble, M.G. Saulnier, Heterocycles 1985 $23,1277$.

[19] V. K. Kansel, P. Potier, Tetrahedron 1986, 42. 2389.

[20] D. Sowmithran, K. J.R. Prasad, Heterocycles $1986,24,711$.

[21] P. Bhattacharyya, B. K. Chowdhury, J. Nat. Prod. $1985,48,465$

[22] U. Pindur, C. Flo, unpublished results and $S y m h$. Commun. 1989, 19, 230 ?

[23] T. Martin, C.J. Moody, J. Chem. Soc., Perkin Trans. 1 1988, 235.

[24] T. Martin, C.J. Moady, J. Chem. Soc., Perkin Trans. 1 1988, 241

[25] K. Ramesh, R.S. Kapil, Indian J. Chem., Sect. B 1986, 25, 462; T.-S. Wu, T. Ohta, H. Furukawa, C.S. Kuoh, Heterocycles 1982, 20, 1267

[26] K. Ramesh, R.S. Kapil, Chem. Ind. (London) $1986,18,614$.

[27] D. Lontsi, J.F. Ayafor, B. L. Sondengam, J.D. Connolly, D.S. Rycroft, Tetrahedron Lett. 1985, 26, 4249

[28] U. Pindur, U. Pister, unpublished results,

[29] R. B. Sharma, R. S. Kapil, Chem. Ind. (London) $1980,12,158$

[30] D.P. Chakraborty, A. Islam, P. Bhattacharyya, $J$ Indian Chem. Soc. 1985, 62, 602.

[3I] S. Roy, S.K. Chatterjee, D.P. Chakraborty, $J$. Indian Chem. Soc. 1985, 62, 673 .

[32] a) D. Sowmithran, K.J. Prased, Heterocycles 1986, 24, 2195; b) P. Bhattacharyya, D.P. Cha kraborty, B.K. Chowdhury, Indian J. Chem., Sect. B 1984, 23, 849 .

[33] D. P. Chakraborty, S. Roy, A. K. Dutta, J. Indian Chem. Soc. 1987, 64, 215

[34] U. Pindur, Heterocycles 1988, 27, 1253; E. Akgün, U. Pindur, Chimia 1985, 39, 264

[35] L. Pfeuffer, U. Pindur, Helv. Chim. Acta 1987, 70 1419.

[36] L. Pfeuffer, U. Pindur, Helv. Chim. Acta 1988, 7I, 467; U. Pindur, M.-H. Kim, Tetrahedron 1989, 45 , 6427; U. Pindur, M.-H. Kim, M. Eitel, Terrahedron Lett. 1990, 3l, 1551.

[37] U. Pindur, H. Erfanian-Abdoust, Chem. Rev $1989,89,1681$.

[38] J.H. Cardelina, M.P. Kirkup, R. E. Moore, J.S Mynderse, K. Seff, C. J. Simmons, Tetrahedron Lett. 1979, 4915.

[39] K. Sakano, S. Nakamura, J. Antibiot. 1980, 33 961 .

40] M. Kancda, K. Sakano, S. Nakamura, Y. Kushi, Y. litaka, Heterocycles 1981, 15, 993.

[4I] T. Naid, T. Kitahara, M. Kaneda, S. Nakamura, J. Antibiot. 1987, 40, 157

[42] S. Kano, E. Sugino, S. Shibuya, S. Hibino, J. Org Chem. 1981, 46, 3856.

[43] T. Kawasaki, Y. Nonaka, K. Sakamoto, J. Chem. Soc., Chem. Commun. 1989, 43.

[44] U. Pindur, L. Pfeuffer, Tetrahedron Lett. 1987, 28 3079.

[45] U. Pindur, L. Pfeuffer, Heterocycles 1987, 26, 325

[46] H.-J. Knölker, M. Bauermeister, D. Bläser, R. Boese, J.-B. Pannek, Angew. Chem. 1989, 101 225; ibid. Int. Ed. 1989, 28, 225; H.-J. Knölker. M. Baumeister, J. Chem. Soc, Chem. Commun. 1989 1468.

[47] C.J. Moody, P. Shah, J. Chem. Soc., Perkin Trans. $/ 1989,376$

[48] J. Bergman, B. Pelcman, Tetrahedron 1988, 44, 5215.

\title{
Matrix-Assisted Laser Desorption and Ionization Mass Spectrometry and Its Applications in Chemistry
}

\section{Introduction}

Since its development in 1988 by Karas and Hillenkamp [1] matrix-assisted laser desorption mass spectrometry (LDI-MS) has received an immensely growing interest. With the fast development of peptide synthesis and genetic engineering in particular, the need for a method which allows to determine the molecular weight of proteins and polypeptides with high accuracy and sensitivity has increased simultaneously. The LDI-MS has the potential to fulfill these needs. The LDI-MS can be used as well to solve analytical and mass-spectrometric problems for other interesting chemical species besides proteins due to its high sensitivity and its low selectivity. The method allows to desorb and ionize large molecules up to $200 \mathrm{kDa}$ and to determine the molecular weight with as little as $100 \mathrm{fmol}$ sample. Thus, the sensitivity of LDI is comparable with other analytical methods like RP HPLC. The method has a dynamic range of at least 1:100 which al-
Abstract. The present paper gives a summary of the potentialities of matrix-assisted laser desorption and ionization mass spectrometry (LDI-MS). Mass spectrometric information on different chemical and biochemical species are obtained with LDI-MS. Sulfonic acids, polysaccharides, oligonucleotides, and peptides were measured as negatively or positively charged ions in a time-of-flight mass spectrometer (TOF-MS). The amount of sample for a measurement lies between $50 \mathrm{pmol}$ and $100 \mathrm{fmol}$ and is, thus, comparable with other analytical and mass spectrometric methods. The large mass range from 0.6 $\mathrm{kDa}$ up to $200 \mathrm{kDa}$ is accessible with LDI-MS. Molecular-weight determination can be done with an accuracy of less than $0.2 \%$. Comparison with RP HPLC reveals the power of LDI-MS as an analytical tool.
* Correspondence: Dr. K.O. Börnsen

Central Analytical Department

Ciba-Geigy Ltd.

$\mathrm{CH}-4002$ Basel 
bazole chemistry. We are also grateful to the Deutsche Forschungsgemeinschaft (Bonn, Bundesrepublik Deutschland), the Fonds der Chemischen Industrie, and Boehringer Ingelheim $K G$ for generous financial support of our synthetic work in this area.

Reccived: February 20, 1990 Revised form: July 7, 1990

[1] J.A. Joule, Adv. Heterocycl. Chem. 1984, 35, 83.

[2] D. P. Chakraborty, Planta Med. 1980, 39, 97

[3] K.S. J. Stapleford, in 'Rodd's Chemistry of Carbon Compounds', Ed. M. F. Ansell, Elsevier, New York, 1985, Vol.IV, Part B, p. 71.

[4] H.P. Husson, in 'The Alkaloids', Ed. A. Brossi, Academic Press, New York, 1985, Vol. 26, p. 1 .

[5] D.P. Chakraborty, in 'Prog. Chem. Org. Nat. Products', Eds. W. Herz, H. Grisebach, and G.W Kirby, Springer Verlag, Vienna, 1977, Vol.34, p. 299

[6] P. Bhattacharyya, D.P. Chakraborty, in 'Prog. Chem. Org. Nat. Products', Eds. W. Herz, H. Grisebach, G.W. Kirby, and Ch. Tamm, Springer Verlag, Vienna, 1987, Vol. 52, p. 159

[7] W. L. Albrecht, R.W. Fleming, W.S. Horgan, G. D. Mayer, J. Med. Chem. 1974, $20,364$.

[8] A. Mooradien, A. G. Havac, P.E. Dupon, M. R Bell, A. D. Abousi, J. Med. Chem. 1975, 18, 640.

[9] N. I. Andreeva, Farmak. Toks. 1967, 36, 713 (CA. $1968,68,57793 \mathrm{r}$ ).

[10] D. P. Chakraborty, K.C. Das, B. K. Chowdhury, Trans. Bose Res. Inst. 1975, 38, I; ibid. 1975, 38, 3

[11] G. D. Shah, B. P. J. Patel, Ind. J. Chem. 1979, 188 451 .

[12] K. Sakano, K. Ishimaru, S. Nakamura, J. Antibiot. 1980, 33, 683; S. Nakamura, Trans. Bose Res. Inst. 1984, 47, 69
[13] T. Tabka, J.-F. Heron, P. Gauduchon, J.-Y. Le Talaer, J.-C. Lancelot, S. Rault, M. Robba, Eur. J. Med. Chem. 1988, 23, 119

[14] U. Pindur, Pharmaz. Uns. Zeit 1987, 16, 47.

[15] M.J.E. Hewlins, A.-M. Oliveira-Campos, P. V. R. Shannon, Synthesis 1985, 289.

[16] P. Potier, Pure Appl. Chem. 1986, 58, 737.

[17] A. Ahond, H. Fernandez, M.-J. Moore, C. Poupat, V. Sanchez, P. Potier, S. K. Kan, T. Sevenet, J. Nat. Prod. 1981, 44, 193.

[18] G.W. Gribble, M.G. Saulnier, Heterocycles 1985 $23,1277$.

[19] V. K. Kansel, P. Potier, Tetrahedron 1986, 42. 2389.

[20] D. Sowmithran, K. J.R. Prasad, Heterocycles $1986,24,711$.

[21] P. Bhattacharyya, B. K. Chowdhury, J. Nat. Prod. $1985,48,465$

[22] U. Pindur, C. Flo, unpublished results and $S y m h$. Commun. 1989, 19, 230 ?

[23] T. Martin, C.J. Moody, J. Chem. Soc., Perkin Trans. 1 1988, 235.

[24] T. Martin, C.J. Moady, J. Chem. Soc., Perkin Trans. 1 1988, 241

[25] K. Ramesh, R.S. Kapil, Indian J. Chem., Sect. B 1986, 25, 462; T.-S. Wu, T. Ohta, H. Furukawa, C.S. Kuoh, Heterocycles 1982, 20, 1267

[26] K. Ramesh, R.S. Kapil, Chem. Ind. (London) $1986,18,614$.

[27] D. Lontsi, J.F. Ayafor, B. L. Sondengam, J.D. Connolly, D.S. Rycroft, Tetrahedron Lett. 1985, 26, 4249

[28] U. Pindur, U. Pister, unpublished results,

[29] R. B. Sharma, R. S. Kapil, Chem. Ind. (London) $1980,12,158$

[30] D.P. Chakraborty, A. Islam, P. Bhattacharyya, $J$ Indian Chem. Soc. 1985, 62, 602.

[3I] S. Roy, S.K. Chatterjee, D.P. Chakraborty, $J$. Indian Chem. Soc. 1985, 62, 673 .

[32] a) D. Sowmithran, K.J. Prased, Heterocycles 1986, 24, 2195; b) P. Bhattacharyya, D.P. Cha kraborty, B.K. Chowdhury, Indian J. Chem., Sect. B 1984, 23, 849 .

[33] D. P. Chakraborty, S. Roy, A. K. Dutta, J. Indian Chem. Soc. 1987, 64, 215

[34] U. Pindur, Heterocycles 1988, 27, 1253; E. Akgün, U. Pindur, Chimia 1985, 39, 264

[35] L. Pfeuffer, U. Pindur, Helv. Chim. Acta 1987, 70 1419.

[36] L. Pfeuffer, U. Pindur, Helv. Chim. Acta 1988, 7I, 467; U. Pindur, M.-H. Kim, Tetrahedron 1989, 45 , 6427; U. Pindur, M.-H. Kim, M. Eitel, Terrahedron Lett. 1990, 3l, 1551.

[37] U. Pindur, H. Erfanian-Abdoust, Chem. Rev $1989,89,1681$.

[38] J.H. Cardelina, M.P. Kirkup, R. E. Moore, J.S Mynderse, K. Seff, C. J. Simmons, Tetrahedron Lett. 1979, 4915.

[39] K. Sakano, S. Nakamura, J. Antibiot. 1980, 33 961 .

40] M. Kancda, K. Sakano, S. Nakamura, Y. Kushi, Y. litaka, Heterocycles 1981, 15, 993.

[4I] T. Naid, T. Kitahara, M. Kaneda, S. Nakamura, J. Antibiot. 1987, 40, 157

[42] S. Kano, E. Sugino, S. Shibuya, S. Hibino, J. Org Chem. 1981, 46, 3856.

[43] T. Kawasaki, Y. Nonaka, K. Sakamoto, J. Chem. Soc., Chem. Commun. 1989, 43.

[44] U. Pindur, L. Pfeuffer, Tetrahedron Lett. 1987, 28 3079.

[45] U. Pindur, L. Pfeuffer, Heterocycles 1987, 26, 325

[46] H.-J. Knölker, M. Bauermeister, D. Bläser, R. Boese, J.-B. Pannek, Angew. Chem. 1989, 101 225; ibid. Int. Ed. 1989, 28, 225; H.-J. Knölker. M. Baumeister, J. Chem. Soc, Chem. Commun. 1989 1468.

[47] C.J. Moody, P. Shah, J. Chem. Soc., Perkin Trans. $/ 1989,376$

[48] J. Bergman, B. Pelcman, Tetrahedron 1988, 44, 5215.

\section{Matrix-Assisted Laser Desorption and Ionization Mass Spectrometry and Its Applications in Chemistry}

\section{Introduction}

Since its development in 1988 by Karas and Hillenkamp [1] matrix-assisted laser desorption mass spectrometry (LDI-MS) has received an immensely growing interest. With the fast development of peptide synthesis and genetic engineering in particular, the need for a method which allows to determine the molecular weight of proteins and polypeptides with high accuracy and sensitivity has increased simultaneously. The LDI-MS has the potential to fulfill these needs. The LDI-MS can be used as well to solve analytical and mass-spectrometric problems for other interesting chemical species besides proteins due to its high sensitivity and its low selectivity. The method allows to desorb and ionize large molecules up to $200 \mathrm{kDa}$ and to determine the molecular weight with as little as $100 \mathrm{fmol}$ sample. Thus, the sensitivity of LDI is comparable with other analytical methods like RP HPLC. The method has a dynamic range of at least 1:100 which al-
Abstract. The present paper gives a summary of the potentialities of matrix-assisted laser desorption and ionization mass spectrometry (LDI-MS). Mass spectrometric information on different chemical and biochemical species are obtained with LDI-MS. Sulfonic acids, polysaccharides, oligonucleotides, and peptides were measured as negatively or positively charged ions in a time-of-flight mass spectrometer (TOF-MS). The amount of sample for a measurement lies between $50 \mathrm{pmol}$ and $100 \mathrm{fmol}$ and is, thus, comparable with other analytical and mass spectrometric methods. The large mass range from 0.6 $\mathrm{kDa}$ up to $200 \mathrm{kDa}$ is accessible with LDI-MS. Molecular-weight determination can be done with an accuracy of less than $0.2 \%$. Comparison with RP HPLC reveals the power of LDI-MS as an analytical tool.
* Correspondence: Dr. K.O. Börnsen

Central Analytical Department

Ciba-Geigy Ltd.

$\mathrm{CH}-4002$ Basel 
lows to detect also minor amounts of impurities in samples. Due to the soft desorption and ionization process which produces no fragments, LDI-MS is especially helpful for the unambiguous determination of the masses of species in mixtures, and is applicable over the whole mass range with a typical accuracy for the molecular-weight determination within $0.2 \%$. The mass resolution $\mathrm{m} / \Delta \mathrm{m}$ obtained is between 100 and 300 depending on the purity of the sample and the mass. The short time (a few min) needed for sample preparation and measurement makes LDI the method of choice for mass-spectrometric analysis in the chemical laboratory. Due to its low selectivity, it will be possible to gain reliable quantitative information on sample concentrations and purities.

\section{Experimental}

\section{Apparatus}

The mass spectrometer used is a home-built linear time-of-flight (TOF) miss spectrometer [2]. The length of the drift tube is $1.7 \mathrm{~m}$. The ion source consists of 3 plates which produce the acceleration field and two plates with which the ion beam can be focussed. The matrix ions and its photo-adducts can be drawn out with two deflection plates. A pulsed laser beam (Quantel Datacltrom $5000 \mathrm{Nd}$ :YAG pumped dye-laser, $330 \mathrm{~nm}, 7 \mathrm{~ns}, 3-12 \mu \mathrm{J})$ is focussed with a quartz lens (12 inch focal length) to an area of $300 \times 600 \mu \mathrm{m}$ on the matrix at an incident angle of $20^{\circ}$. This relatively large illuminated area eliminated the effects of inhomogeneities in the crystalline structure of the matrix. The ions are accelerated in an electric field of $+20 \mathrm{kV}$ for the negative or $-20 \mathrm{kV}$ for the positive ions. The detector is a Galiteo 2 "-tandem multichannel plate with the entrance plate held at $-3 \mathrm{kV}$.

The probe tip is made of stainless steel and coated with a $\mathrm{Ag}$ or $\mathrm{Au}$ layer and has a $1.5 \mathrm{~mm}$ diameter.

The data acquisition system consisted of Tektronix/ Sony 710 A transient recorder connected via IEEE-bus to a HP 9836 computer. The registration of the analogue signal was performed at a rate of $100 \mathrm{MHz}$. A fast light-sensitive diode was used to start the acquisition. For a mass spectrum between 5 and 90 single shots were summed in order to optimize the signal-to-noise ratio. No background subtraction has been performed.

Matrix and Sample Preparation

$0.1 \mathrm{M}$ sinapinic acid (3,5-dimethoxy-4-hydroxycinnamic acid, Fluka 85430 ) dissolved in $50 \% \mathrm{MeCN}$ and $50 \%$ of a $90 \%$ aq. EtOH soln. was used for all experiments, because of its low sublimation rate, high protein yield up to $200 \mathrm{kDa}$, and acceptable small amounts of photo-adducts.

Typically $S \mu \mathrm{l}$ of $0.1 \mathrm{M}$ sinapinic acid and $5 \mu \mathrm{l}$ of a $10^{-5} \mathrm{M}$ aq. soln. of the protein were mixed. $0.1 \%$ $\mathrm{CF}_{3} \mathrm{COOH}$ was added to solns. of samples with low solubility in $\mathrm{H}_{2} \mathrm{O} .0 .5 \mu$ lo the mixture was added to the probe tip the solvents were rapidly evaporated by vacuum, and the probe tip was inserted into the mass spectrometer.

Contamination of the sample with salt in high concentration can reduce the ion yield. Sodium ions, however, have no significant effect on the negative ion signal intensity up to a 10 -fold molar excess. Sodium dodecyl sulfate-polyacrylamide used in SDS-PAGE on the other hand can completely quench the ion production even in low concentrations. It is not yet clear, if this contaminant lcads to a phase separation during the drying process of the matrix [3].

\section{Mass Calibration}

In time-of-flight mass spectrometry the flight time $t$ of an ion is correlated with its mass $m$ over a simple relationship:

$\sqrt{\frac{m}{z}}=A t+B$ where $A$ and $B$ are calibration constants which depend on the strength of the electric field and the length of the drift tube. Using a standard of known mass allows to determine the constants $A$ and $B$

We have used two methods for the mass calibration of LDI-MS measurements. "The first method uses the ion signals of the matrix and its photo-adducts. Sinapinic acid forms adducts which are especially dominant in the negative-ion spectra and are, thus, ideal for mass calibration. Although these signals are in the low-mass region, they can be used for a calibration range up to $30000 \mathrm{Da}$ with an error limit of $0.2 \%$.

The second method uses proteins of known mass as standards. The measurements in this paper were calibrated with the following compounds: trypsin (bovine, Fluka 93612, mol. wt. $=23311$ [4]) and albumin (bovine, Serva 11923, mol. wt. $=66267[4]$ ). $0.5 \mu \mathrm{l}$ of a $10^{-5} \mathrm{M}$ aq. protein soln. can be added to the existing matrix. The base peak and the ion signal of the dimer can then be used for calibration. This method gives the best results for high masses.

With a more sophisticated algorithm for the time-tomass conversion and with the use of an internal calibrant, Beavis et al. could achieve an accuracy for mass determination of $\pm 0.01 \%$ [5].

\section{Applications}

The following figures present possible applications of LDI-MS. In a first example, we show the accessible mass range with LDI-MS using a low-mass and a highmass protein. In a second example, it is shown which chemical classes besides proteins can be measured with this method. The third example finally describes an analytical application where the resolving power of LDI-MS in comparison with RP HPLC is demonstrated.

The autors would like to point out that all the examples shown in this paper were measured with the same standard method described above with no special optimization for different samples. We have intended to demonstrate that the LDI-MS method can be used very easily leading to acceptable results.

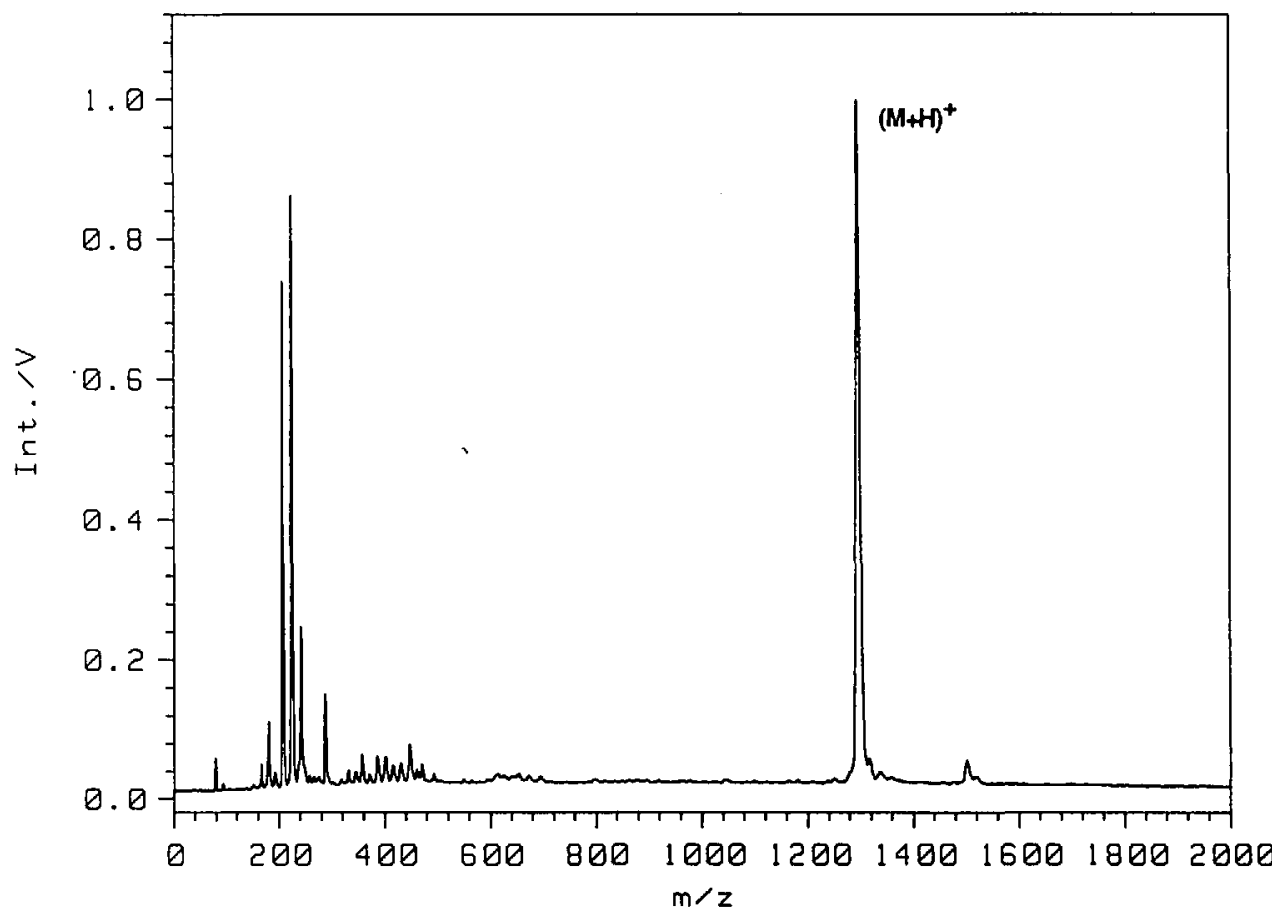

Fig. 1. Positive LDI mass spectrum of angiotensin I. 5 shots were summed.

\subsection{Mass Range}

The LDI-MS method can be applied to detect molecular ions in the range from 0.6 $\mathrm{kDA}$ up to $200 \mathrm{kDA}$. The low-mass range limit is given by the strong signals originating from the sinapinic acid and its photoadducts which can hide the ion signal of interest. The laser has to be operated at the threshold of sample ion production in order to keep the matrix signal as low as possible. The dynamic range allows already to detect signals down to only about $1 \%$ of the matrix-signal intensity. Together with a better stabilization of the laser power output, it will be possible to further decrease the low-mass limit.

Fig. I shows the 10-amino-acid peptide angiotensin I (synthetic, human form, Sigma A9650) with a calculated molecular weight of $1296.51 \mathrm{Da} \cdot 0.5 \mu \mathrm{l}$ of a $2 \cdot 10^{-5} \mathrm{M}$ aq. solution was used. The determined mass $([M+\mathrm{H}])$ is $1296.9 \pm 1.2 \mathrm{Da}$. The accuracy of the molecular-mass determination in the low-mass range is better than $0.1 \%$ (while it is between $0.3 \%$ and $0.2 \%$ in the high-mass range). This is due to the narrower peak width (FWHM) of low mass signals compared to the FWHM of high-mass signals.

The other ion signals detected below 700 $\mathrm{Da}$ in Fig. 1 origin from the sinapinic acid and its photo-adducts. The ion signal at the mass of $1502 \mathrm{Da}$ has $2 \%$ intensity of the $[M+\mathrm{H}]^{+}$signal. This low signal origins from the angiotensin I molecule with an attached sinapinic-acid residue of mass 206 $\mathrm{Da}$. The production of this photo-adduct can be controlled by the laser power output, but it cannot be completely suppressed. The peak width (FWHM) is narrow, indicating high purity of the peptide. Note the very low background. The smallest ion signals between 700 and 1400 $\mathrm{Da}$ are impurities produced during the syn- 


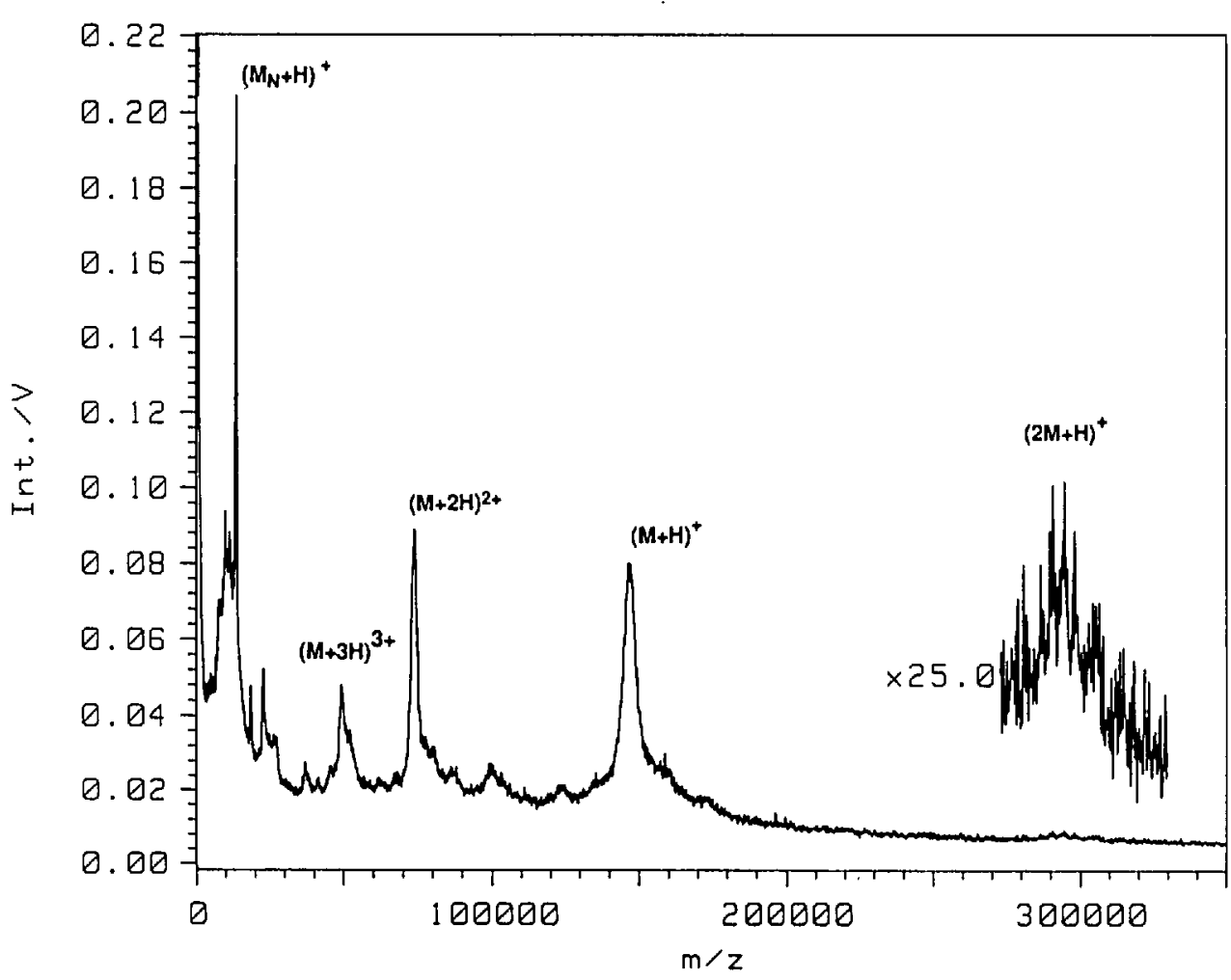

Fig. 2. Positive LDI mass spectrum of $\gamma$-globulin. 32 shots were summed.

thesis of the angiotensin I (see also Sect.3.3). Although the ration of mols of sinapinic acid $v s$. angiotensin in the matrix is $5000: 1$, the ratio of the ion signal intensities is about $1: 1.3$.

Fig. 2 shows a positive-ion mass spectrum of $\gamma$-globulin. $0.5 \mu \mathrm{l}$ of a $1 \cdot 10^{-6} \mathrm{M}$ aq. solution of $\gamma$-globulin (bovine, Serva 22550 ) corresponding to a total amount of 500 fmol. The molecular ion at $147240 \pm 0.3 \% \mathrm{Da}$ is the base peak Doubly and triply charged molecular ions with comparable intensity can also be detected. Between 280000 and $300000 \mathrm{Da}$ the broad ion signal of the dimer $[2 \mathrm{M}+\mathrm{H}]^{+}$ is registered. The real mass of $\gamma$-globulin is not known. According to the supplier the mass of $\gamma$-globulin is $c a$. $169000 \mathrm{Da}$ (determined with SDS-PAGE). To explain the lower experimental mass, fragmentation of the $\gamma$-globulin can be ruled out, because the measured mass of the dimer ion suggests that the molecular weight of $\gamma$-globulin has to be below 150000 . No higher monomer or dimer signals can be observed. If we had fragmentation, the completely missing masses above $150000 \mathrm{Da}$ would indicate that the fragmentation process has an efficiency of $100 \%$, which is very unlikely. Until now, no LDI-MS-induced fragmentation has been observed [1-5] [6]. The dimer signal is low in intensity, but it shows that the desorption/ionization process must be very soft, because it does not break the weak dimer bond. The intensity of the dimer ion signal is dependent on the protein concentration in the matrix.

The strong signal below 1000 Da origins from the matrix ions which are not completely removed by the draw out pulse. The high mass limit is in first order dependent on the sensitivity of the detection system tained show no difference in signal intensities, peak widths and determined masses for peptides and proteins. The amounts of photo-adducts, however, are slightly higher in the positive-ion mode. To extend the field of applications, we have tested the applicability of LDI-MS on oligonucleotides, polysaccharides, and sulfonic acids.

\subsubsection{Oligonucleotide}

Most of the current activities in analytical biochemistry and technology focus on the characterization and modification of biomacromolecules. The availability of a fast and sensitive mass spectrometric method in this field is highly desirable, especially in the light of DNA sequencing and the Human Genome Initiative [8]. As an example in this class of biomacromolecules, we have measured a commercially available decamer oligonucleotide $\operatorname{pd}(T)$ (thymidine) as sodium salt with a theoretical mass of $3059.2 \mathrm{Da}$ for the free acid.

Fig. 3 shows the negative-ion mass spectrum taken from a $2 \cdot 10^{-5} \mathrm{M}$ sample. $0.5 \mu \mathrm{l}$ were used as matrix. Spengler et al. [9] have measured oligonucleotides as positive ions, but we have found a much better signal-tonoise ratio for negative ions. At the mass of $3133 \pm 0.1 \% \mathrm{Da}$, the main peak of the negatively charged decamer $\mathrm{pd}(\mathrm{T})$ can be detected. The dimer signal appears at $6270 \pm 0.1 \% \mathrm{Da}$ which gives a mass for the monomer of $3135 \mathrm{Da}$. The low-ion signal at the mass $1570 \mathrm{Da}$ origins from the doubly charged monomer. The peak shape of the monomer ion signals reveals two masses which lie within 32 Da and, thus, cannot be completely resolved.

At $2828 \pm 0.1 \%$, the signal of a degraded decamer $\mathrm{pd}(\mathrm{T})$ which has lost one thymidine nucleotide can be detected. The

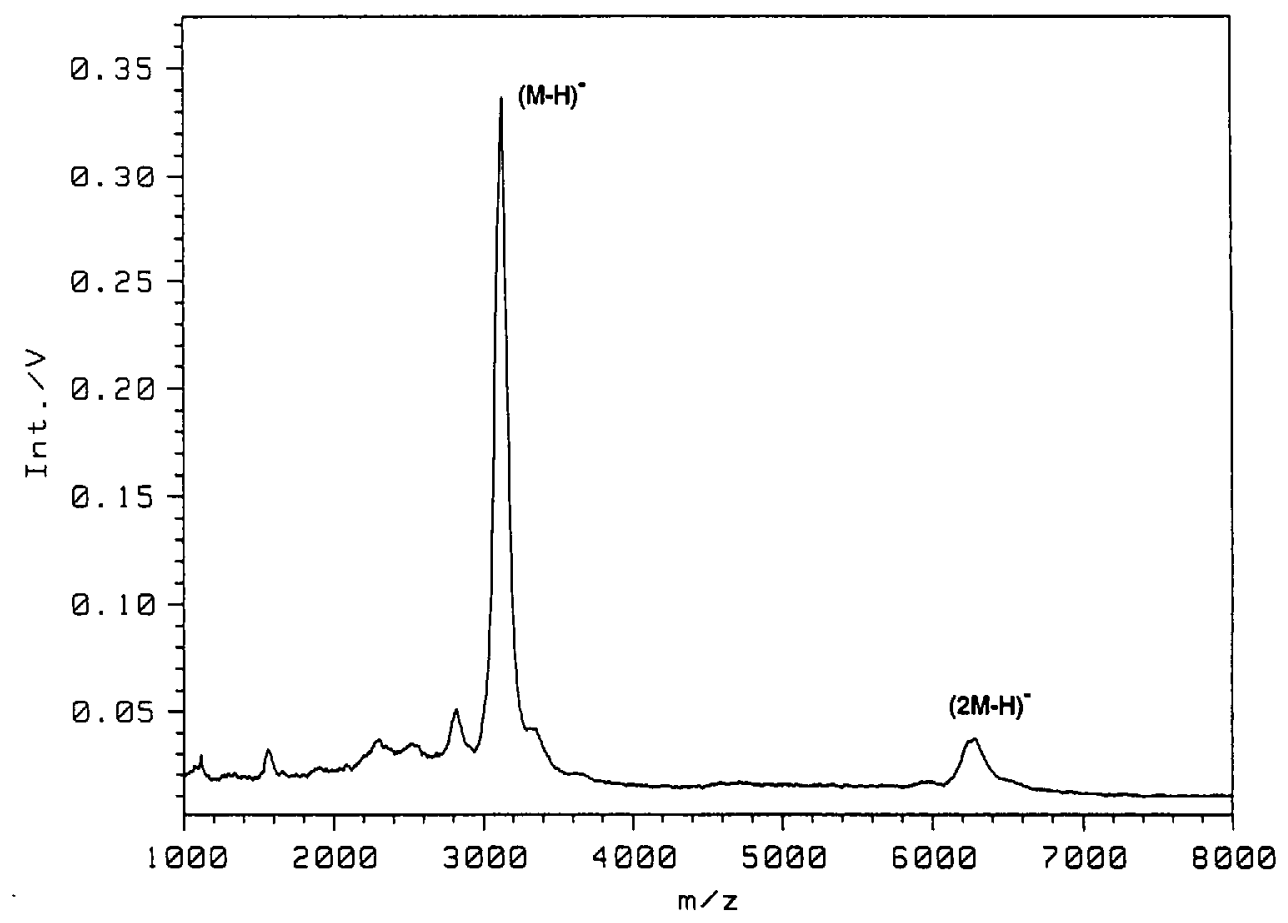

Fig. 3. Negative LDI mass spectrum of 10-mer of $p d(T)$. 16 shots were summed. 
mass for the thymidine nucleotide is 304.1 $\mathrm{Da}$, whereas the measured mass difference is $305 \mathrm{Da}$.

The large mass difference of $74 \mathrm{Da}$ between the measured and the calculated mass of the oligonucleotide lies outside the typical accuracy for the mass determination of $0.1 \%$. Different measurements and methods for the calibration and the timeto-mass conversion procedure gave the same result. We have measured the same sample with $0.1 \mathrm{M}$ 2,5-dihydroxybenzoic acid instead of sinapinic acid as matrix and found a different peakshape and mass (data not shown). Therefore, the higher mass can be explained with the addition of sinapinic acid matrix fragments. Oligonucleotides with thymidine gave highest signal intensities. This indicates that thymidine and sinapinic acid can form complexes which produce specific photoadducts upon laser desorption and ionization. Thus, a new matrix molecule has to be found which forms only little or no photo-adducts with oligonucleotides.

Nevertheless, oligonucleotides can be detected with LDI-MS and it is possible to determine DNA sequences with this method.

\subsubsection{Polysaccharide}

A further chemical substance of interest are carbohydrates, i.e. starch or polysaccharides. We have used $\gamma$-cyclodextrin consisting of 8 maltose units (Fluka 28708 , mol. wt. $=1297.14 \mathrm{Da})$. The purity was better than $98 \%$ according to the supplier. $0.5 \mu \mathrm{l}$ of $2 \cdot 10^{-5} \mathrm{M}$ aq. solution was used. Fig. 4 shows the mass spectrum of $\gamma$-cyclodextrin, measured in the negative-ion mode. The main ion signal has a mass of $1298.9 \pm 0.1 \%$ Da. No multicharged ions or complexed systems were found. The low-intensity ion mass origins from the $\gamma$ -

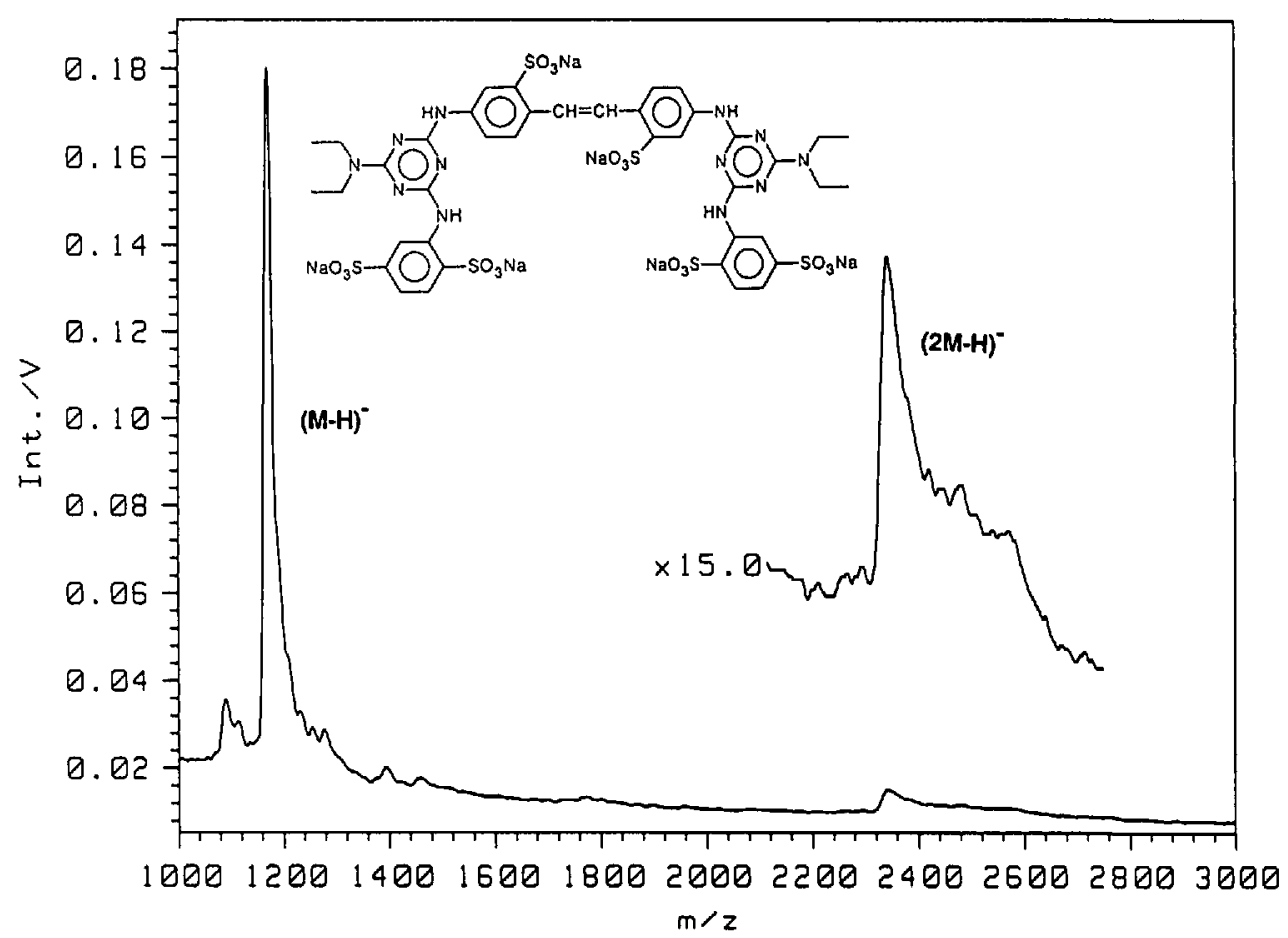

Fig. 5. Negative LDI mass spectrum of a sulfonic acid. 16 shots were summed.

cyclodextrin molecule with an attached sinapinic acid residue of mass $206 \mathrm{Da}$. At $1120 \mathrm{Da}$, the low-ion signal from the pentamer sinapinic acid can be detected. The strong background can be due to unresolved photochemically produced complexes from the sinapinic acid and to the unknown impurities contained in the $\gamma$-cyclodextrin sample.

\subsubsection{Sulfonic Acid}

Another chemical substance of interest are sulfonic acids, especially because they are used in dye stuff production. The molecule measured in Fig. 5 consists of 6

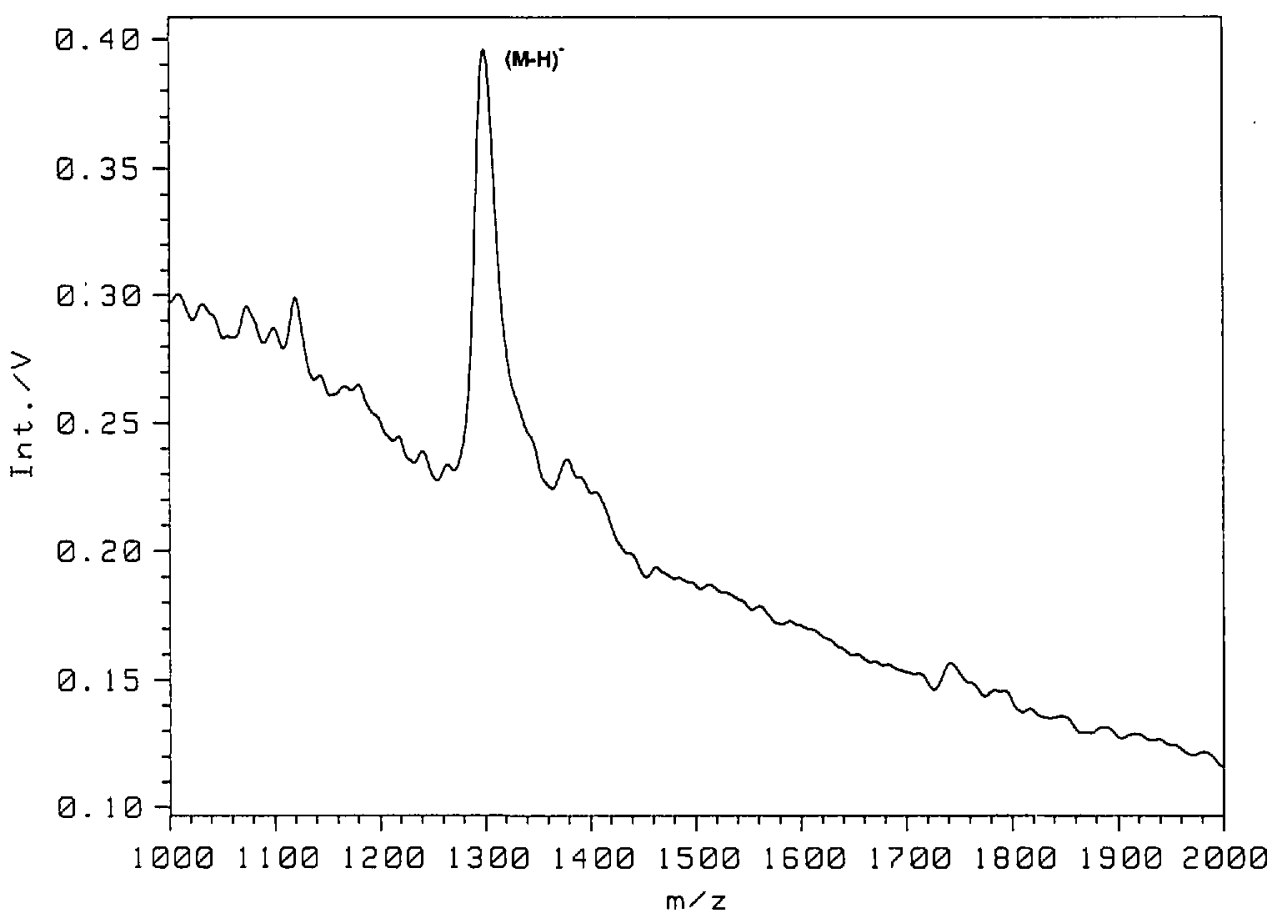

Fig. 4. Negative LDI mass spectrum of $\gamma$-cyclodextrin. 12 shots were summed. sulfonic acids coupled to a brightener. The mass spectrum was measured in the negative mode with about $50 \mathrm{pmol}$ amount of sample used. Sulfonic acids gave ion signals only in the negative mode. Interestingly, the sulfonic acid, although existing in the matrix as $\mathrm{Na}$ salt, can only be detected as a free acid. No alkali ion adduct has been found. Similar results were obtained with oligonucleotides. The most intense peak at $1173.8 \mathrm{Da}$ is the base peak of $[M-\mathrm{H}]^{-}$whereas the signal at $2350.9 \mathrm{Da}$ origins from the dimer ion $[2 M-\mathrm{H}]^{-}$. The calculated molecular weight is 1173.23 Da. The accuracy of the mass determination was $0.1 \%$. All other detected peaks origin from unknown impurities.

\subsection{Analytical Power of LDI-MS}

Due to its high sensitivity and low selectivity LDI-MS can be used for solving analytical problems where other methods like RP HPLC have not the desired resolving power. In Figs. 6 and 7 the characterization of a synthetic 19-amino-acid peptide and its by-products is given. The peptide was assembled using a standard procedure for solid-state synthesis. After each coupling step unreacted $\alpha$-amino-acid groups were acetylated. Fig. 6 shows the RP HPLC chromatogram of the crude product. Note that the main peak is saturated. Only minor amounts of impurities were found and the determined purity is $99 \%$.

Fig. 7 shows the LDI-MS spectrum of the same sample. $0.5 \mu \mathrm{l}$ of $2 \cdot 10^{-5} \mathrm{M}$ aq. solution was used. The preparation and measuring time was $c a .6$ min which is significantly faster than the time needed for a RP HPLC measurement.

At least 13 different species can be distinguished in this sample. All detected ion signals can be explained in terms of the 


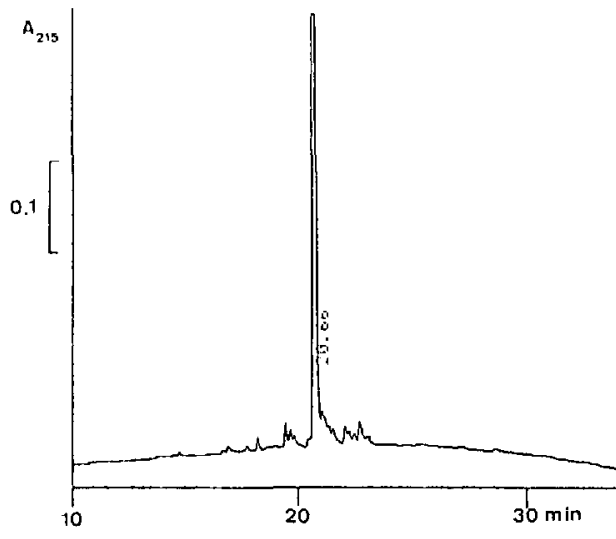

Fig.6. Reversed-phase high performance liquid chromatography of a crude synthetic 19-amino-acid peptide. Conditions: column, Nucleosil C18 $(250 \times 4.6 \mathrm{~mm}$ I.D. $)$; linear gradient $(3 \% \mathrm{~B} / \mathrm{min})$, where solvent $A$ is $0.1 \%$ TFA in $\mathrm{H}_{2} \mathrm{O}$ and solvent $\mathrm{B} 0.1 \%$ TFA in MeCN (pH 2.0); flow-rate $1 \mathrm{ml}$ / min.

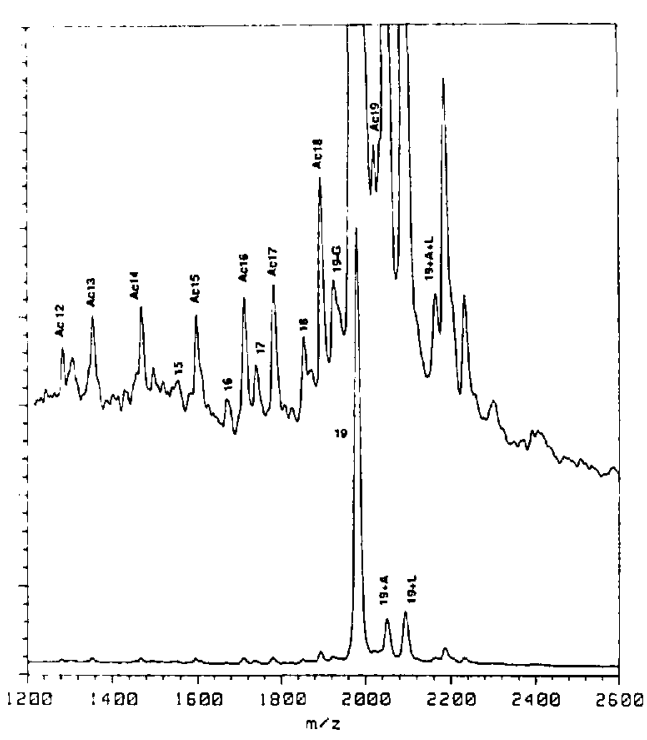

Fig. 7. Negative LDI mass spectrum of a crude synthetic 19-amino-acid peptide. 90 shots were summed.

used synthesis. In the Table, the masses and their interpretation are summarized. The measurement showed that the majo impurities are not, as expected, due to incomplete coupling but to impurities (dipeptides) of the amino-acid derivates used. Incorporation of dipeptides lead to insertions and, thus, higher masses. Furthermore, the mass spectrum shows an incomplete acetylation [10]. The obtained accuracy of the mass determination is very good and lies between 0.07 and $0.03 \%$. The intensities of the ion signals cannot be correlated with the actual concentrations. Relative concentrations can be given, if the

Table. Characterization of a Synthetic 19-Amino-Acid Peptide and its By-products. Sequences of peptide 19 and expected by-products: A: alanine; $G$ : glycine; L: leucine; $K$ : lysine.

\begin{tabular}{lllll}
\hline Peptide & Sequence & $\begin{array}{l}M_{\mathrm{r}}[\mathrm{Da}] \\
\text { Calc. }\end{array}$ & $\begin{array}{l}M_{\mathrm{r}}[\mathrm{Da}] \\
\text { Exper. }\end{array}$ & $A$ \\
\hline $19+\mathrm{A}+\mathrm{L}$ & & 2160.8 & 2159.4 & 1.4 \\
$19+\mathrm{L}$ & & 2089.7 & 2089.2 & 0.5 \\
$19+\mathrm{A}$ & & 2047.6 & 2047.2 & 0.4 \\
Ac19 & & 2018.7 & 2017.9 & 0.7 \\
19 & KLALKLALKALKLALKLAG & 1976.6 & .1976 .8 & 0.2 \\
$19-\mathrm{G}$ & KLALKLALKALKLALKLA & 1919.6 & 1919.8 & 0.2 \\
Ac18 & Ac LALKLALKALKLALKLAG & 1890.5 & 1889.8 & 0.7 \\
18 & LALKLALKALKLALKLAG & 1848.5 & 1848.7 & 0.2 \\
Ac17 & Ac ALKLALKALKLALKLAG & 1777.3 & 1777.1 & 0.2 \\
17 & ALKLALKALKLALKLAG & 1735.2 & 1734.4 & 0.8 \\
Ac16 & Ac LKLALKALKLALKLAG & 1706.2 & 1706.8 & 0.6 \\
Ac15 & Ac KLALKALKLALKLAG & 1593.1 & 1592.7 & 0.4 \\
Acl4 & Ac LALKALKLALKLAG & 1464.9 & 1465.4 & 0.5 \\
\hline
\end{tabular}

mass difference between the ion signals compared are not more than about 8000 Da. The intensities of detected by-products in Fig. 7 are $1-2 \%$ of the 19 -amino-acid ion intensity. Both can be detected which gives a dynamic range of $1: 100$ for the LDI-MS method.

\section{Conclusion}

In this paper, we have presented LDIMS measurements of different chemical and biochemical substances without a special method optimization. The goal was to demonstrate that LDI-MS can be used as an easy, fast, and sensitive standard method for a broad field of chemicals. LDI-MS is still under development and the photochemical processes in the matrices are not yet understood (there exists only a few theoretical approaches [11]).

The method is already helpful for the unambiguous determination of the masses of species in mixtures and is applicable over a large mass range up to $200 \mathrm{kDa}$ with an accuracy for the molecular-weight determination of typically $0.2 \%$. Because the desorption and ionization process of LDIMS produces negative and positive ions, different chemical substances as polypeptides, proteins, oligonucleotides, polysaccharides, and sulfonic acids can be detected. The low selectivity towards different chemical substances will allow to gain reliable quantitative determination of sample concentrations and purities.

The comparison of RP HPLC and LDIMS demonstrates the analytical power of the latter. LDI-MS measurements can be performed within minutes with almost no sample preparation needed, and the ob- tained amount of information is high. Due to its advantages LDI-MS will soon establish as a state-of-the-art mass spectrometric and analytical method in any chemical laboratory for the detection and mass determination of by-products and contaminants of an ongoing synthesis, for characterization of new batches in biomolecular synthesis of proteins, for the qualitative determination of the purity of the detected proteins, and it can be used for optimizing synthetic strategies. Finally, the kinetics of biochemical reactions can be monitored by mass analysis after given time intervals.

We would like to thank $V$. Steiner for measuring the RP HPLC chromatogram and for the characterization of the LDI-MS spectrum of the 19-amino-acid peptide.

Received: November 16, 1990

[I] M. Karas, F. Hillenkamp, Anal. Chem. 1988, 60 2299. M. Karas, U. Bahr, F. Hillenkamp, Int. J. Mass Spectrom. Ion Proc. 1989, 92, 231.

[2] K.O. Börnsen, M. Schär, V. Steiner, Ernst Gassmann, submitted to Biomed. Environ. Mass Spec.

[3] M. Karas, A. Ingendoh, U. Bahr, F. Hillenkamp, Biomed. Environ. Mass Spectrom. 1989, 18, 841 .

[4] R.C. Beavis, B.T. Chait, Rapid Commum. Mass Spectrom. 1989, 3. 233

[5] R.C. Beavis, B.T. Chait, Anal Chem. 1990, 62, 1836.

[6] B. Spengler, R.J. Cotter, Anal. Chem. 1990, 62, 793. M. Salehpour, I. Perera, J. Kjellberg, A. Hedin, M.A. Islamian, P. Hàkansson, B.U.R. Sundqvist, Rapid Commen. Mass Spectrom. 1989, 3,259 .

[7] R. J. Beuhler, J. Appl. Phys. 1983, 54, 4118

[8] G. L. Trainor, Anal. Chem. 1990, 62, 418.

[9] B. Spengler, Y. Pan, R. J. Cotter, L.S. Kan, Rapid Commun. Mass Spectrom. 1990, 4, 99.

[10] V. Steiner, K.O. Börnsen, M. Schär, Pept. Res., in preparation.

[11] A. Vertes, R. D. Levine, Chem. Phys, Lett. 1990, 171,284 